\title{
Dose Motor Inhibition Response Training Using Stop-signal Paradigm Influence Execution and Stop Performance?
}

\author{
Sung Min Son \\ Department of Physical Therapy, College of Health Science, Cheongju University, Cheongju, Korea
}

Purpose: This study examined whether 1) the motor inhibition response as cognitive-behavioral component is learning though a stop signal task using stop-signal paradigm, and 2) whether there is a difference in the learning degree according to imagery training and actual practice training.

Methods: Twenty young adults (males: 9, females: 11) volunteered to participate in this study, and were divided randomly into motor imagery training $(I T, n=10)$ and practice training (PT, $n=10)$ groups. The PT group performed an actual practice stop-signal task, while the IT group performed imagery training, which showed a stop-signal task on a monitor of a personal computer. The non-signal reaction time and stop-signal reaction time of both groups were assessed during the stop-signal task.

Results: In the non-signal reaction time, there were no significant intra-group and inter-group differences between pre- and post-intervention in both groups $(p>0.05)$. The stop-signal reaction time showed a significant difference in the PT group in the intra-group analysis $(p<0.05)$. On the other hand, there was no significant intra-group difference in the IT group and inter-group difference between preand post-intervention $(p>0.05)$.

Conclusion: These results showed that the motor inhibition response could be learned through a stop-signal task. Moreover, these findings suggest that actual practice is a more effective method for learning the motor inhibition response.

Keywords: Motor imagery, Stop-signal paradigm, Stop signal task, Motor inhibition response

\section{서 론}

수행하는 행동의 실행적 제어는 특정한 행동적 목표 성취나 충동적 인 행동을 억제하기 위한 행위일 뿐만 아니라 동작의 순서에 포함된 요소들을 적절하게 선택하기 위해 인지-행동(cognitive behavior) 처리 과정이 필요한 복잡하고 연합적인 고위 인지기능이다.1.2 실행적 제어 에서 동작정지기능은 동작의 정보 처리과정 중 계획된 동작에 대한 음성적 피드백 혹은 부적절한 충동적 동작이 억제성 활동으로 나타 나는 인지-운동적 처리과정이라고 할 수 있다.34 동작정지를 위한 운 동반응 억제 기능은 목표에 도달하기 위해 동작을 최적의 방향으로 바꾸기 위한 첫 단계이며, 인지적 제어에 있어 가장 일반적인 필요 사 항이다.56 이러한 동작정지를 위한 운동반응 억제는 행동의 유연성을 위해 필수적이고 다양하게 변화하는 주위 환경에 적응하기 위해서 많은 경험과 학습을 통해 이루어진다. ${ }^{5}$

부적절한 행동(action)을 억제하기 위한 능력은 적절한 목표-지항

Received Mar 5, 2020 Revised Apr 7, 2020

Accepted Apr 14, 2020

Corresponding author Sung Min Son

E-mailssm0417@hanmail.net
적인 행위(behavior)를 달성하기 위해 기초적인 요소이고, 정지신호 패러다임(stop-signal paradigm)을 이용한 정지신호과제(stop-signal task)는 동작정지능력의 반응억제(response inhibition) 진행에 대한 시 간적 경로(time course)의 평가를 제공함으로써 많은 인지과학, 인지 신경학 및 정신병리학 등의 연구 분야에서 많이 사용되고 있다.7.8 정 지신호 패러다임은 반대 조건(opposing requirements)을 가진 두 가지 과제 사이에 균형(trade-off) 요소와 관련되어 있으며, 주어진 자극에 가능한 빠른 반응이 필요한 진행과제(go task)와 다른 하나는 정지 신 호가 나타났을 때 실행 반응을 정지하는 정지과제(stop task)로 구성 되어 있다.' 정지신호 패러다임은 동작 수행의 반응억제 진행에 대한 시간적 경로를 평가하기 위해 정지신호반응시간(stop-signal reaction time, SSRT)을 측정함으로서 확인할 수 있으며, 진행과제에 반응하는 시간을 측정한 운동반응시간(non-signal reaction Time, NSRT)과 시각 적 진행과제를 제시한 이후 청각적 정지신호가 제시될 때가지의 시 간을 의미하는 정지신호지연(Stop Signal Delay)의 관계를 설명하는 
함수를 통해 정지신호반응시간이 결정되어진다. ${ }^{10,11}$

빠른 반응이 필요한 진행 과제와 연관된 뇌 영역은 대뇌겉질(cortex), 바닥핵(basal ganglia), 시상(thalamus)과 대뇌 겉질로 되돌아가는 대뇌겉질-바닥핵-시상겉질(cortico-basal ganglia-thalamocortical circuit) 연결 회로이며, ${ }^{12}$ 운동반응억제와 관련한 뇌 영역은 이마엽-바닥 핵 회로(fronto-basal gangalia circuit)로서 아래 이마엽이랑(inferior frontal gyrus), 중간 이마엽이랑(middle frontal gyrus), 안쪽 이마엽이랑 (medial frontal gyrus)과 기저핵이 포함된다.3,13 선행 연구들에서 주의 력 결핍 및 과잉 행동(attention deficit hyperactivity disorder), 강박증 (obsessions) 및 틱(tic) 장애를 가진 사람들에서는 동작을 정지하기 위 한 운동반응 억제 기능이 결핍되어 있다고 보고되었으며, ${ }^{14,15}$ 운동반 응억제와 관련한 이마엽-바닥핵 회로의 기능과 구조적인 차이를 가 지고 있다고 하였다. 하지만, 선행연구들에서 성공적인 운동반응억 제를 달성했을 때, 이마엽-바닥핵 주위의 활성도가 증가하였다고 보 고하였으며, 이는 지속적인 자극의 입력은 뇌 가소성 및 운동반응억 제의 학습으로도 이어질 수 있을 것이라 생각되어진다. ${ }^{16,17}$

지금까지 연구들은 지속적인 과제 훈련을 통해 운동 수행 능력 (motor performance capacity)이 자동적인 운동학습으로 연계되어지 는지 확인한 연구들이 대부분이며, 본 연구에서 사용한 정지신호 패 러다임을 이용하여 운동 억제 반응(motor inhibition response)에 대한 인지- 행동 학습에 관한 연구는 없었다. 따라서 본 연구의 목적은 정 지신호 패러다임을 이용한 정지신호과제 훈련이 인지-행동학적 요소 인 운동 반응억제에서도 학습이 이루어지는지 확인하는 것이며, 추 가적으로 심상훈련(imagery training) 방법과 실질적인 수행 훈련에 따른 학습 정도의 차이가 있는지 알아보고자 한다.

\section{연구 방법}

\section{1. 연구대상}

본 연구는 20 명의 건강한 젊은 성인 대상자가 참여하였으며, 대상자 들은 과제 수행 방식에 따라심상 훈련 그룹(10명)과 실제 수행훈련 그 룹(10명)으로 무작위 배정하였다. 대상자들의 선별 기준은 다음과 같 다. 1) 최근 1 년 이내에 상지(upper extremity)의 근골격계 질환 및 현재 상지의 통증이 없는 자, 2) 신경학적 혹은 정신적 문제가 없는 자, 3) 과 제 수행에 영향을 줄 수 있는 시각 및 청각적 문제가 없는 자로 하였 다. 대상자는 비우세손을 사용하여 과제를 수행하였으며, 비우세손 은 축구공을 발로 찼을 때 축이되는 쪽을 비우세측으로 하였다. 모 든 대상자들에게 연구의 목적과 방법을 충분히 설명하였고, 이에 실 험에 자발적으로 동의하고 참여한 대상자들로 하였다.

\section{2. 정지신호과제}

정지신호과제는 제시되는 자극에 가능한 빠른 반응을 요구하는 진 행과제와 제시되는 자극에 대해 정지 반응을 요구하는 정지과제로 구성되어 있으며, 시각적 자극으로 제시되는 진행과제에 대해 가능 한 빠르게 동작 실행 반응을 보이거나 진행과제가 주어진 후에 짧은 청각적 신호를 제시하였을 때 동작 실행을 취소하는 반응이 나타나 도록 설계되었다. 본 연구에서 사용된 정지신호과제는 $75 \%$ 의 진행과 제와 $25 \%$ 의 정지과제가 무작위 순서로 제공되었다. 진행 과제는 시각 적 자극으로서 모니터 중앙에 검정 바탕의 흰색의 사각형 혹은 원형 모양의 도형이 제시되며, 정지과제는 진행과제와 동일하게 일차적인 사각형 혹은 원형 모양의 시각적 자극이 주어진 후 반응의 정지를 제 시하는 청각적 자극인 "삐” 소리가 나도록 하였다. 제공되는 시각적 자극은 대상자가 과제 수행을 완료하거나 혹은 반응이 없는 경우 $1,250 \mathrm{~ms}$ 후 다음 자극으로 진행되도록 설계되었다.

본 연구에서는 정지신호과제를 측정하기 위해 STOP-IT 프로그램 (Universiteit Gent, Belgium)을 사용하였으며, 과제 수행을 위해 개인용 컴퓨터를 이용하여 진행하였다. 정지신호과제에서 측정되는 변수로서 운동반응시간과 정지신호반응시간을 확인하기 위해 STOP-IT 분석프 로그램(ANALYZE-IT, Univers iteit Gent, Belgium)을 이용하였다. 운동 반응시간과 정지신호반응시간을 측정하기 위해 평균 운동반응시간 에서 정지신호지연시간을 감하여 구한다. 정지신호과제는 운동반응 정지 확률이 $50 \%$ 가 되도록 조절하기 위해서 과제수행의 성공 여부에 따라 정지신호지연시간이 달라지게 설정되어 있다. 초기 신호정지지연 시간은 $250 \mathrm{~ms}$ 으로 시작하고 정지 과제를 성공할수록 $50 \mathrm{~ms}$ 씩 증가하 며, 이에 반해 정지과제 수행에 실패하면 $50 \mathrm{~ms}$ 씩 감소하게 설계되었다.

정지신호반응시간 $=$ 평균 운동반응시간-반응지연지연시간 (SSRT

$=$ Mean NSRT-SSD)

대상들에게 제시된 정지신호과제는 1 번의 연습 구간과 3 번의 검사 구간으로 이루어져 있으며, 연습 구간에서는 32 회 자극이 제공되고 검사 구간에서는 64 회의 자극이 3 번 제공될 수 있도록 구성되어 있어 총 224회의 자극이 제시되도록 설계되었다. ${ }^{18}$

\section{3. 실험 절차}

모니터에 제시되는 자극의 유형에 따라 진행과제에서는 비우세손으 로 사각형(ロ)일 때는 "V" 혹은 원형(O) 일 때는 "N" 버튼을 누르게 하 였고, 진행과제가 주어진 후 청각적 정지 신호가 제시되면 진행과제 실 행을 취소하게 하였다. 대상자들은 편하게 의자에 앉은 자세를 취하였 으며, 시각적 자극이 제시되는 모니터는 전방 $70 \mathrm{~cm}$ 정도의 거리에 위 치 시켰고 실험 동안 청각적 자극으로서 제시되는 반응 정지 신호 이외 에 다른 청각적 자극에 영향을 받지 않기 위해 이어폰을 사용하였다.

수행 그룹은 자극의 유형에 따라 동작정지신호과제를 실제로 수 
행하도록 하였고, 심상훈련 그룹은 수행 그룹과 동일한 조건에서 실 질적인 과제 수행은 이루어지지 않고 각 자극의 유형에 따라 심상 훈 련을 수행하도록 하였다. 두 그룹 모두 5일동안 하루 2회씩 5일동안 총 10 회의 동작정지신호과제훈련을 실시하였고, 훈련 전-후 평가를 실시하였다. 동작정신호과제 훈련 및 측정 동안 두 그룹에서 제시되 는 과제 프로그램의 동일성 및 적합성을 유지하기 위하여 동일한 프 로그램을 사용하였으며, 각 훈련 및 측정 시간은 1 회에 10 분 정도 소 요되었다. 전-후 측정 평가에서 과제수행 정확도가 $85 \%$ 미만인 경우 대상자들의 집중 및 다른 요인에 의한 오류로 인식하여 5 분간의 휴 식을 가진 후 재 측정을 실시하였다.

\section{4. 자료분석}

본 연구에서 수집된 자료는 SPSS 22.0 버전을 사용하여 통계 처리하 였으며, 유의 수준은 0.05 로 설정하였다. 두 그룹 사이에 나이, 키, 몸 무게와 같은 일반적 특성은 기술통계 및 독립 t-test (independent t-tes) 를 이용하여 비교하였다. 두 그룹 사이에 훈련의 전-후 비교는 Wilcoxon 부호 순위 검정(Wilcoxon signed ranks test) 을 사용하였으며, 집 단 간 전-후 차이를 비교하기 위해서 Mann-Whitney U-검정(MannWhitney U-test)을 이용하였다.

Table 1. The general characteristics of subjects

\begin{tabular}{lccc}
\hline & PT group $(\mathrm{n}=10)$ & $\mathrm{IT}$ group $(\mathrm{n}=10)$ & $\mathrm{p}$ \\
\hline Male/Female & $4 / 6$ & $5 / 5$ & \\
Age (yr) & $21.5 \pm 1.51$ & $21.5 \pm 1.78$ & 1.000 \\
Height & $169.60 \pm 8.91$ & $171.20 \pm 12.25$ & 0.742 \\
Weight & $64.50 \pm 13.56$ & $65.60 \pm 16.36$ & 0.872 \\
\hline
\end{tabular}

Mean \pm SD.

\section{결 과}

본 연구에 참여한 대상자는 실제 수행 훈련 그룹과 심상 훈련 그룹 10 명씩 전체 20명으로 구성되었다. 성별, 나이, 키 및 몸무게와 같은 일 반적 특성에서는 두 그룹 사이에서 유의한 차이는 없었다 $(\mathrm{p}>0.05)$ (Table 1).

정지 신호 과제 훈련에 따른 운동 반응 시간의 전-후 비교에서 심 상 훈련 그룹과 실제 수행 훈련 그룹에서 모두 유의한 차이가 없었고 ( $\mathrm{p}>0.05)$, 두 그룹 사이의 전-후차이 값 비교에서도 유의한차이가 없 었다( $\mathrm{p}>0.05)$ (Table 2). 정지 신호 과제 훈련에 따른 정지 반응 시간의 전-후 비교에서 실제 수행 훈련 그룹에서는 유의한 차이가 있었으며 $(\mathrm{p}<0.05)$, 심상 훈련 그룹에서는 유의한 차이가 없었다 $(\mathrm{p}>0.05)(T a b l e$ 3). 두 그룹 사이의 전-후 차이 값 비교에서는 유의한 차이가 없었다 $(\mathrm{p}>0.05)$.

\section{고 찰}

본 연구에서는 정지신호 패러다임을 이용하여 인지-행동학적 운동 반응 억제에 대한 학습 효과를 확인하기 위하여 심상 훈련 그룹과 실 제 수행 훈련 그룹으로 나누어 정지신호과제 훈련을 실시하였다. 본 연구의 결과에서 심상 훈련 그룹과 실제 수행훈련 그룹 모두 훈련 전 과 비교했을 때 진행과제에서 측정 된 운동반응시간에서는 유의한 차이가 없었다. 정지과제에서 측정 된 정지신호반응시간에서 훈련 전-후 심상 훈련 그룹에서는 약간의 시간적 감소는 보였지만, 유의한 차이는 없었다. 실제 수행 훈련 그룹에서는 훈련 전후 유의한 시간적 감소를 나타내었다. 두 그룹 간 비교에서 운동반응시간과 정지반응 시간 모두 실제 훈련 그룹과 심상 훈련 그룹 사이에 유의한 시간적 차

Table 2. Comparison of the NSRT between the pre- and post-test in both group

\begin{tabular}{lcccc}
\hline & Pre $(\mathrm{ms})$ & Post $(\mathrm{ms})$ & Difference value & $p$ \\
\hline PT group $(n=10)$ & $800.85 \pm 126.66$ & $805.94 \pm 169.04$ & $-5.09 \pm 114.60$ & 0.959 \\
IT group $(n=10)$ & $846.34 \pm 104.99$ & $906.41 \pm 122.94$ & $-60.07 \pm 92.41$ & 0.070 \\
$p$ & & & 0.253 & \\
\hline
\end{tabular}

Mean \pm SD

NSRT: non-stop reaction time, PT: practice training group, IT: image training group.

Table 3. Comparison of the SSRT between the pre- and post-test in both group

\begin{tabular}{lcccc}
\hline & Pre $(\mathrm{ms})$ & Post $(\mathrm{ms})$ & Difference value & $\mathrm{p}$ \\
\hline PT group $(\mathrm{n}=10)$ & $243.52 \pm 40.81$ & $215.66 \pm 25.92$ & $-27.86 \pm 40.27$ & $0.007^{\star}$ \\
IT group $(n=10)$ & $240.66 \pm 25.60$ & $230.14 \pm 33.27$ & $-10.52 \pm 34.01$ & 0.169 \\
$p$ & & & 0.190 & \\
\hline
\end{tabular}

Mean \pm SD

SSRT: stop signal reaction time, PT: practice, IT: image training group.

${ }^{*} \mathrm{p}<0.05$. 
이는 없었다.

본 연구에서 정지신호 과제의 진행 과제에서 측정되는 운동반응 시간에서 그룹 내 비교와 그룹 간 비교에서 모두 유의한 차이가 없었 다. 훈련 전-후 그룹 내 비교에서 심상 훈련 그룹은 진행 과제를 수행 하는 운동반응시간이 다소 증가하였으며, 실제 수행 훈련 그룹에서 는 운동반응시간에 차이를 보이지 않았다. 이러한 연구 결과가 나타 난 원인은 본 연구에서 사용한 정지신호 과제 훈련이 자극에 대해 빠 른 반응을 요구하는 진행과제와 자극에 대해 정지 반응을 요구하는 정지과제가 무작위 순서로 제시되어 두 과제에 대한 예측이 불가능하 며, 정지과제가 성공할수록 신호정지지연 시간이 점차 증가하도록 설 계되어 있어 대상자들은 진행과제에 대한 빠른 반응이 적어진다고 할 수 있다. ${ }^{19}$ 이러한 반응의 변화는 성공적인 과제 수행을 위해 무작위 순서로 제시되는 두 가지 상반된 과제(진행과제와 정지과제) 사이에 서 조정된 반응 전략을 통해 최적의 균형적인 반응을 수립해 나가는 과정으로 해석할 수 있다." 또한, 본 연구는 정지신호가 제시될 경우 반응을 멈추는 과제가 포함되어 있어 대상자들이 진행 과제를 수행 하는 동안 상대적으로 빠른 반응을 보이지 않아 나타난 결과로 사료 되어진다. ${ }^{20}$ 추가적으로 Verbruggen 와 $\operatorname{Logan}^{21}$ 은 진행과제 시 성공적 인 빠른 반응은 정지신호 과제에 대한 불이행을 시사할 수 있으며, 정 지과제에 대한 성공적인 과제 수행은 과제 수행 시 빠르게 반응을 수 행하지 않고 느린 반응을 선택한 결과로 의미할 수 있다고 하였다.

정지과제에서 측정 된 정지신호반응시간은 훈련 전-후 두 그룹에 서 모두 시간적 감소가 나타났으며, 실제수행훈련 그룹에서만 유의 한 차이를 보였다. 본 연구 결과를 토대로, 인지-행동학적 요소인 운 동 반응억제는 정지 과제 훈련을 통해 학습이 이루어질 수 있음을 확 인하였다. 심상훈련은 신체 움직임 없이 시각 및 청각적 자극을 이용 하여 머리속으로 어떠한 행동을 상상함으로써 간접적인 운동 감각 경험을 얻는 과정을 의미한다.22,23 선행 연구들에서 심상훈련은 인지행동학적 학습이 덜 소요되는 공 던지기나 혹은 다크 던지기와 같은 단순한 과제 수행에서도 운동 기능의 향상이 나타난다고 하였다. ${ }^{24}$ 또한, Yeo 등 25 의 연구에서 심상훈련이 시열 반응과제와 같은 인지-행 동학적 능력이 필요한 수행 과제에서도 기능 향상을 이끌 수 있음을 확인하였다. 이러한 심상을 통한 움직임 과정에 대한 상상은 운동 수 행의 준비 단계에서 나타날 수 있는 동작의 오류 및 비효율성을 감소 시킬 수 있으며, ${ }^{26}$ 심상 훈련을 통한 움직임의 향상은 운동 영역 뿐만 아니라 인지적 영역에 영향을 주어 운동 학습의 효율성을 증진시킬 수 있는 방법이다. Wilson 등 ${ }^{27}$ 의 연구에서도 협응 운동장애(impaired motor coordination)를 가진 아동을 대상으로 심상훈련 그룹과 실제 인지 운동 훈련(perceptual-motor training) 그룹으로 나누어 5 주간 중 재를 실시한 결과 심상훈련 그룹이 실제 인지 운동 훈련 그룹과 거의 동일한 운동수행능력의 향상이 나타났다고 보고하였다. 이러한 심
상 운동의 효과에 대한 기전은 fMRI 검사를 통한 대뇌 겉질(brain cortex) 활성화에 패턴 및 근활성도 변화 대한 연구에서 확인할 수 있 다. Nyberg 등 ${ }^{28}$ 의 연구에서는 손가락 탭핑과제(taping task)에 대한 실 제 훈련 그룹과 동작을 상상한 심상 훈련 그룹에서 모두 운동 관련 대뇌 겉질에서 활성도가 증가한 것을 확인하였고, Bonnet 등 29 의 연구 에서는 심상과제 훈련 동안 근전도에서 $\mathrm{H}$-반사 강도가 증가하여 심 상 훈련이 근육의 활성도를 증가 시킬 수 있음을 확인하였다.

하지만, 본 연구에서는 과제 훈련 전-후를 비교했을 때 심상 훈련 그룹에서는 유의한 차이를 보이지 않아 심상 훈련이 수행 능력의 향 상을 이끌 수 있다는 선행 연구들의 결과와 차이를 보였다. 이와 같은 본 연구 결과는 실제 수행 훈련과 심상 훈련의 수행 방법의 차이에 의 해서 나타난 결과라 생각된다. 실제 수행 훈련 그룹이 심상훈련 그룹 에 비해 인지-행동학적 능력을 바탕으로 반복적인 신체 움직임을 이 용한 연습 통해 점차적으로 시간이 경과하면서 정지신호과제에 대 한 반응이 습관화 또는 자동화 되어 운동 학습이 이루어져 나타난 결과라 할 수 있다. ${ }^{30}$ 이 연구의 결과를 토대로, 실제 훈련 방법이 운동 심상 훈련에 비해 운동반응 억제에 대한 학습에 더 효율적일 수 있음 을 시사한다.

본 연구 결과를 바탕으로 정지신호 패러다임을 이용한 반응억제 훈련 과제는 충동적인 혹은 행동 억제가 어려운 대상자들의 행동학 적 변화를 야기시킬 수 있는 중재 방법으로도 사용할 수 있는 근거 토대를 확인한 연구라 할 수 있다. 하지만, 본 연구는 고려해야 할 몇 가지 제한점을 가지고 있다. 첫번째, 본 연구에서는 대상자의 표본 크 기가 작아 일반화 하기 어렵다는 것이다. 두 번째, 본 연구에서는 젊은 건강한 성인을 대상으로 실시한 연구로서 인지-행동학적 충동 결함 을 가진 대상자에게 동일하게 일반화 시키기에 어려움이 있다. 따라 서, 향후 연구에서는 이러한 제한점을 보완한 추가적이 연구들이 시 행되어야 할 것이다.

\section{ACKNOWLEDGEMENTS}

This work was supported by the research grant of Cheongju University (2018.09.01-2020.08.31).

\section{REFERENCES}

1. Duncan J, Owen AM. Common regions of the human frontal lobe recruited by diverse cognitive demands. Trends Neurosci. 2000;23(10): 475-83.

2. Goghari VM, MacDonald AW 3rd. The neural basis of cognitive control: Response selection and inhibition. Brain Cogn. 2009;71(2):72-83.

3. Aron AR. The neural basis of inhibition in cognitive control. Neurosci- 
entist. 2007;13(3):214-28.

4. Miyake A, Friedman NP, Emerson MJ et al. The unity and diversity of executive functions and their contributions to complex "frontal lobe" tasks: A latent variable analysis. Cogn Psychol. 2000;41(1):49-100.

5. Badry R, Mima T, Aso T et al. Suppression of human cortico-motoneuronal excitability during the stop-signal task. Clin Neurophysiol. 2009; 120(9):1717-23.

6. Barkley RA. Behavioral inhibition, sustained attention, and executive functions: Constructing a unifying theory of adhd. Psychol Bull. 1997; 121(1):65-94.

7. Verbruggen F, Liefooghe B, Vandierendonck A. Selective stopping in task switching: The role of response selection and response execution. Exp Psychol. 2006;53(1):48-57.

8. Verbruggen F, Logan GD. Models of response inhibition in the stop-signal and stop-change paradigms. Neurosci Biobehav Rev. 2009;33(5): 647-61.

9. Logan GD, Van Zandt T, Verbruggen F et al. On the ability to inhibit thought and action: General and special theories of an act of control. Psychol Rev. 2014;121(1):66-95.

10. Band GP, van der Molen MW, Logan GD. Horse-race model simulations of the stop-signal procedure. Acta Psychol. 2003;112(2):105-42.

11. Verbruggen F, Logan GD. Response inhibition in the stop-signal paradigm. Trends Cogn Sci. 2008;12(11):418-24.

12. Alexander GE, Crutcher MD, DeLong MR. Basal ganglia-thalamocortical circuits: Parallel substrates for motor, oculomotor, "prefrontal" and "limbic" functions. Prog Brain Res. 1991;85:119-46.

13. Rubia K, Smith AB, Taylor E et al. Linear age-correlated functional development of right inferior fronto-striato-cerebellar networks during response inhibition and anterior cingulate during error-related processes. Hum Brain Mapp. 2007;28(11):1163-77.

14. Enticott PG, Ogloff JR, Bradshaw JL. Response inhibition and impulsivity in schizophrenia. Psychiatry Res. 2008;157(1-3):251-4.

15. Geurts HM, Verte S, Oosterlaan J et al. How specific are executive functioning deficits in attention deficit hyperactivity disorder and autism? J Child Psychol Psychiatry. 2004;45(4):836-54.

16. Aron AR, Poldrack RA. The cognitive neuroscience of response inhibition: Relevance for genetic research in attention-deficit/hyperactivity disorder. Biol Psychiatry. 2005;57(11):1285-92.

17. Kieling C, Goncalves RR, Tannock R et al. Neurobiology of attention deficit hyperactivity disorder. Child Adolesc Psychiatr Clin N Am. 2008;17(2):285-307.

18. Verbruggen F, Logan GD, Stevens MA. Stop-it: Windows executable software for the stop-signal paradigm. Behav Res Methods. 2008;40(2): 479-83.

19. Chikazoe J, Jimura K, Hirose S et al. Preparation to inhibit a response complements response inhibition during performance of a stop-signal task. J Neurosci. 2009;29(50):15870-7.

20. Verbruggen F, Logan GD. Automaticity of cognitive control: Goal priming in response-inhibition paradigms. J Exp Psychol Learn Mem Cogn. 2009;35(5):1381-8.

21. Verbruggen F, Logan GD. Proactive adjustments of response strategies in the stop-signal paradigm. J Exp Psychol Hum Percept Perform. 2009; 35(3):835-54.

22. Guillot A, Collet C. Contribution from neurophysiological and psychological methods to the study of motor imagery. Brain Res Brain Res Rev. 2005;50(2):387-97.

23. Solodkin A, Hlustik P, Chen EE et al. Fine modulation in network activation during motor execution and motor imagery. Cereb Cortex. 2004;14(11):1246-55.

24. Mendoza D, Wichman H. "Inner" darts: Effects of mental practice on performance of dart throwing. Percept Mot Skills. 1978;47(3 Pt 2):11959.

25. Kim CS, Yeo SS, Park SY. The effects of motor learning through the mental imagery training on task performance and motor learning component. Journal of Special Education \& Rehabilitation Science. 2010;49(4): 221-36.

26. Richard Schmidt TL. Motor control and learning: A behavioral emphasis.4th ed. Human kinetics, 2005.

27. Wilson PH, Adams IL, Caeyenberghs K et al. Motor imagery training enhances motor skill in children with dcd: A replication study. Res Dev Disabil. 2016;57:54-62.

28. Nyberg L, Eriksson J, Larsson A et al. Learning by doing versus learning by thinking: An fmri study of motor and mental training. Neuropsychologia. 2006;44(5):711-7.

29. Bonnet M, Decety J, Jeannerod M et al. Mental simulation of an action modulates the excitability of spinal reflex pathways in man. Brain Res Cogn Brain Res. 1997;5(3):221-8.

30. Seger CA. Implicit learning. Psychol Bull. 1994;115(2):163-96. 